\title{
Simultaneous elimination of Malachite Green, Rhodamine B and Cresol Red from aqueous sample with Sistan sand, optimized by Taguchi L16 and Plackett-Burman experiment design methods
}

\author{
Sahar Marghzari ${ }^{1}$, Mojtaba Sasani ${ }^{2}$, Massoud Kaykhaii ${ }^{1,3^{*}} \mathbb{D}$, Mona Sargazi $^{1}$ and Mohammad Hashemi ${ }^{4}$
}

\begin{abstract}
The purpose of this study was to investigate the feasibility of simultaneous optimization and removal of dyes, Malachite green (MG), Rhodamine B (RhB) and Cresol Red (CR) from aqueous solutions by using Sistan sand as an extremely low cost adsorbent. Factors affecting adsorption of the analytes on the sorbent were investigated experimentally and by using Taguchi and Plackett-Burman experimental design methods. In most cases, the results of these two models were in agreement with each other and with experimental data obtained. Taguchi method was capable to predict results with accuracies better than $97.89 \%, 95.43 \%$, and $97.79 \%$ for $M G$, RhB, and CR, respectively. Under the optimum conditions, the sorbent could remove simultaneously more than $83 \%$ of the dyes with the amount of adsorbed dyes of $0.132,0.109$, and $0.120 \mathrm{mg} \mathrm{g}^{-1}$ for MG, RhB and CR on sand, respectively. Kinetic studies showed that pseudo second order is the best model of adsorption for all analytes. Thermodynamic parameters revealed that this process is spontaneous and endothermic.
\end{abstract}

Keywords: Simultaneous removal of dyes, Taguchi design, Plackett-Burman design, Malachite green, Rhodamine B, Cresol red, Sand

\section{Introduction}

Industrial wastewater is one of the major pollutants of the environment. Colored wastewaters are produced in many industries such as textile, pharmaceutical, food, cosmetic and leather industries [1,2]. Annually, more than 10,000 metric tons of dyes are consumed in textile industries which makes their wastewater as one of the most important environmental pollutants [3]. Typically, the main pollutant in textile wastewater is organic dyes which many of them are resistant to biodegradation. Moreover, colored wastewater prevents the penetration of sunlight into the water and reduces the speed of

\footnotetext{
*Correspondence: kaykhaii@chem.usb.ac.ir

1 Department of Chemistry, Faculty of Sciences, University of Sistan and Baluchestan, Zahedan 98155-674, Iran

Full list of author information is available at the end of the article
}

photosynthetic process [4-7]. More importantly, their carcinogenic effects and genetic mutations in living organisms are proved $[8,9]$. Therefore, it is of importance to maintain human and environmental healthy by removing dyes using cheap and economical methods. Various methods have been evaluated for this purpose, such as electrochemical coagulation, using membranes, photocatalytic techniques, electrochemical methods, biological processes and adsorption techniques [3]. Since adsorption process is the most economical method and has a simpler operational capability, in most cases, it is preferred to other techniques $[10,11]$. Nano-particles are of high interest for simultaneous removal of dyes nowadays. For example, cobalt hydroxide nano-particles were applied for simultaneous removal of Indigo Carmine and Methyl orange [12]. In another study, four toxic dyes including Brilliant Green, Auramine O, Methylene Blue 
and Eosin Yellow were removed by $\mathrm{CuO}$ Nano-particles loaded on activated carbon [13]. While nano-particles show good performance and high capacity, synthesis of them needs high skill and pure materials are needed; so, most of these materials are not produced in large quantities. Consequently, they are not available in sufficient bulk to be commercialized for full-scale application. Because of these drawbacks, many researchers tried to find cost-effective adsorbents to eliminate dyes [14, 15]. Natural sands contain active components that can strongly adsorb positively charged organic material from an aqueous solution. The potential of using sand for this purpose has been studied and results were promising [16, 17]. However, we could not find any report on applying sand for simultaneous removal of dyes.

For optimization of the parameters affecting adsorption efficiency, it is very common to use one-factorat-a-time (OFAT) method, in which all parameters are keeping constant while one factor is optimized. In this method, it is assumed that each parameter is completely independent of the others. There are obvious advantages for design of experiment (DOE) methods over OFAT, including less resource requirements; ability to assess the effect of factors precisely; and finally by this method, interaction between factors is not neglected [18-20]. Taguchi method is one of these DOE methods which is mainly developed for optimization. By using Taguchi method, the impact of each controllable factor can be determined as well [21]. Plackett-Burman Design (PBD) is a well-established and widely used statistical technique for selecting the most effective components affecting adsorption process with high significance levels for further optimization [22].

In this study, very cheap sand sorbent is used for simultaneous removal of three dyes, Malachite green, Rhodamine B and Cresol Red from water samples and in order to find the optimum conditions for this process, Taguchi design was used. This method selected because it has some advantages over other traditional uni-variant optimization techniques, including less number of experiments is required [23-25]. Moreover, PlackettBurman design was also applied for the same purpose and results were compared to Taguchi design. ANOVA was used to determine and confirm the results obtained experimentally.

\section{Experimental}

Instruments and materials

Sand which was used in this study as dye sorbent was collected from Sistan desert, south east of Iran. MG (catalog number 1013980025), RhB (catalog number 1075990025) and CR (catalog number 1052250005) dyes were purchased from Merck KGaA, Darmstadt, Germany. Table 1 shows physical and chemical characteristics of these

Table 1 Physical and chemical characteristics of adsorbates

\begin{tabular}{|c|c|c|c|}
\hline Dye & Chemical structure & $\begin{array}{l}\text { Molecular weight } \\
\left(\mathrm{g} \mathrm{mol}^{-1}\right)\end{array}$ & $\lambda_{\max }(\mathrm{nm})$ \\
\hline Malachite green & 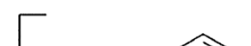 & 364.92 & 618 \\
\hline Rhodamine B & & 479.02 & 554 \\
\hline Cresol red & $\mathrm{HO}$ & 382.43 & 425 \\
\hline
\end{tabular}


adsorbates. Other solvents and reagents were purchased from Fluka AG (Switzerland). Stock solutions of dyes were prepared by dissolving $0.5 \mathrm{~g}$ of each dye in distilled water in $1000 \mathrm{~mL}$ volumetric flasks. The test solution containing a mixture of MG, RhB and CR were prepared daily by diluting the proper volume of stock solution in deionized water. $\mathrm{pH}$ meter (model EasySeven, Metrohm, Switzerland) was applied to measure the $\mathrm{pH}$ of sample solutions. In order to determine the residual concentration of dyes after adsorption, UV-Vis spectrophotometer (model Lambda 25, Perkin Elmer Corp., USA) was used. Sistan sands were characterized by scanning electron microscope (SEM, model EM3900M, KYKY, China) and Fourier transform (FT-IR) spectroscopy (Spectrum two FTIR, Perkin Elmer Corp., USA). Minitab 16 and Qualitek 4 softwares (version 14.7.0) were used for PBD and Taguchi design methods, respectively.

\section{Analytical procedure}

In order to study the efficiency of simultaneous removal of MG, RhB and CR by sand, batch technique was used for their adsorption; and to optimize parameters affecting adsorption, design experiments according to Taguchi design L16 was employed (Fig. 1). Experiments were performed in 6 steps: (1) $20 \mathrm{~mL}$ solution of 3-dyes mixture, with the concentrations mentioned in Additional file 1: Table S1, was prepared in a $50 \mathrm{~mL}$ flask. (2) $\mathrm{pH}$ of the sample solution was adjusted either by $0.1 \mathrm{M} \mathrm{HCl}$ or $0.1 \mathrm{M} \mathrm{NaOH}$. (3) Appropriate amounts of $\mathrm{NaCl}$ and adsorbent were added to the flask carefully. (4) Sample was shaked on a shaker for a preset time to reach equilibrium state. (5) This mixture was centrifuged for $10 \mathrm{~min}$ at $5000 \mathrm{rpm}$ (1957 relative centrifugal force) to separate adsorbent particles from the solution and supernatant liquid were collected. (6) The concentration of dyes remained in the sample after removal of the dyes, was determined spectrophotometerically against a blank in the wavelengths mentioned in Table 1. External calibration curves were used.

After then, the percentage of each dye adsorbed was calculated using equation (1) 12]:

$$
\% \text { Removal }=\frac{C_{0}-C_{e}}{C_{0}} \times 100
$$

where $\mathrm{C}_{\mathrm{e}}$ and $\mathrm{C}_{0}$ are equilibrium and initial dyes concentration $\left(\mathrm{mg} \mathrm{L}^{-1}\right)$ respectively.

In adsorption studies, $\mathrm{q}_{\mathrm{e}}\left(\mathrm{mg} \mathrm{g}^{-1}\right)$ is the amount of adsorbed dye on sorbent in equilibrium state and it can be calculated according to equation (2) [26]:

$$
q_{e}=\frac{\left(C_{0}-C_{e}\right) \times V}{m}
$$

where $\mathrm{C}_{0}$ and $\mathrm{C}_{\mathrm{e}}\left(\mathrm{mg} \mathrm{L}^{-1}\right)$ are respectively the concentration of dyes at initial point and at equilibrium, $\mathrm{V}(\mathrm{L})$ is the volume of the solution and $\mathrm{m}(\mathrm{g})$ is the mass of dry adsorbent used.

\section{Taguchi design of experiments}

Figure 1 depicts the experiments design procedure [27, 28]. Analysis of variances (ANOVA) and signal to noise $(\mathrm{S} / \mathrm{N})$ ratio (SNR) are two main statistical methods which can confirm the results obtained by Taguchi method [29]. SNR is a ratio of mean response (as signal) to standard deviation (as noise) [30]. In this way, bigger $\mathrm{S} / \mathrm{N}$ is desirable and bigger characteristic for $\mathrm{S} / \mathrm{N}$ formula is defined as equation (3) [31]:

$$
\frac{\mathrm{S}}{\mathrm{N}}=\frac{-10 \log \left(\frac{1}{\mathrm{y}_{1}^{2}}+\frac{1}{\mathrm{y}_{2}^{2}}+\cdots+\frac{1}{\mathrm{y}_{\mathrm{n}}^{2}}\right)}{\mathrm{n}}
$$

where $\mathrm{n}$ is number of replications $\mathrm{s}$, and $\mathrm{y}_{\mathrm{i}}$ is the response of detector.

Since the process of simultaneous removal of MG, RhB and CR was desired, 5 factors in 4 levels were chosen and L16 was offered by Qualitek 4 (Table 2). Consequently, 16 experiments were designed. Additional file 1: Table S1 shows the factors and levels which were used in these set of experiments. After doing experiments, optimum levels for each factor were determined by $\mathrm{S} / \mathrm{N}$ and mean of mean (Table 3).

\section{Results and discussion Morphology and characterization of adsorbent}

As can be seen in scanning electron microscope (SEM) image of Sistan sand (Fig. 2), it has an irregular and fractured surface structure. The average size of adsorbent particles was $250 \mu \mathrm{m}$ which was determined using Image software. The FT-IR spectrum of sand (Additional file 1: Figure S1) shows a main peak at $1004 \mathrm{~cm}^{-1}$ which refers to quartz. Presence of quartz is also proved by absorption bands at 1004, 776, 695, 531 and $462 \mathrm{~cm}^{-1}$. A peak at $2347 \mathrm{~cm}^{-1}$ can be assigned to silane [32].

\section{Effect of factors affecting concurrent adsorption of MG, RhB and CR}

To obtain the best performance of the adsorption process for simultaneous removal of three target dyes and achieving satisfactory efficiency in the shortest possible time, several parameters influencing adsorption were studied and optimized while all target compounds were exist in the sample solution. The parameters studied were the amount of sorbent, $\mathrm{pH}$ of sample solution, effect of contact time, ionic strength of the sample solution, and 


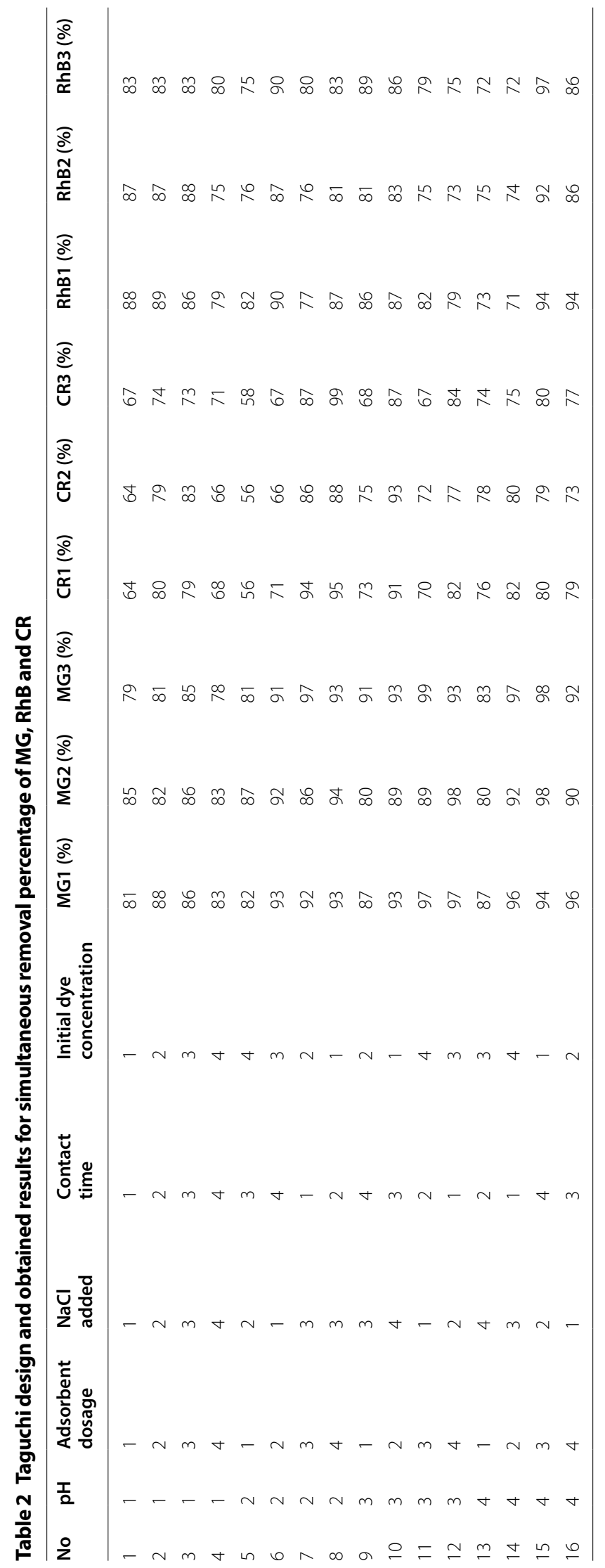




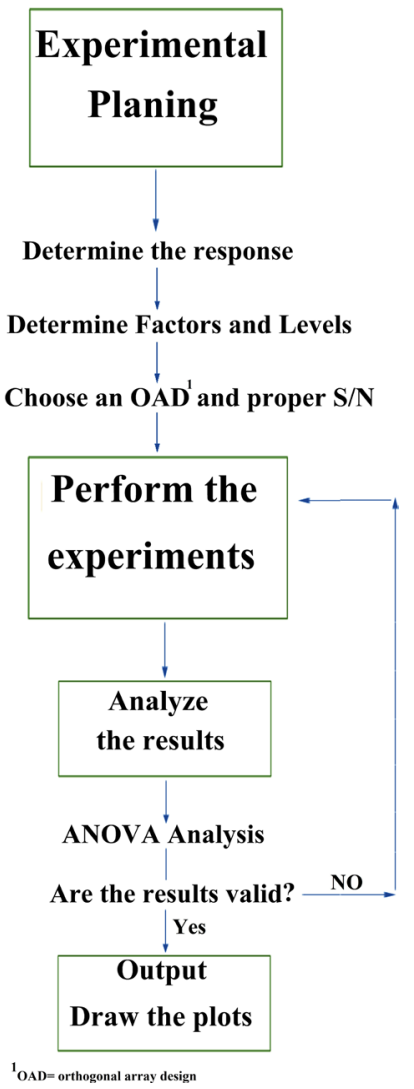

Fig. 1 Procedure of Taguchi design method

Table 3 Optimum conditions for each factor to simultaneous removal of MG, RhB and CR

\begin{tabular}{llllll}
\hline & pH & $\begin{array}{l}\text { Adsorbent } \\
\text { dose }\end{array}$ & $\begin{array}{l}\text { NaCl } \\
\text { added }\end{array}$ & $\begin{array}{l}\text { Contact } \\
\text { time }\end{array}$ & $\begin{array}{l}\text { Initial dye } \\
\text { concentration }\end{array}$ \\
\hline $\mathrm{S} / \mathrm{N}$ & 3 & 2 & 3 & 2 & 3 \\
$\begin{array}{c}\text { Mean of } \\
\text { mean }\end{array}$ & 3 & 2 & 3 & 2 & 3 \\
\hline
\end{tabular}

initial concentration of each dye. Each experiment was run in triplicates.

\section{Effect of $p H$}

Initial $\mathrm{pH}$ of sample solution has a great effect on adsorption capacity. In order to find the effect of $\mathrm{pH}$ on simultaneous adsorption of MG, RhB and CR on Sistan sand, $\mathrm{pH}$ of solutions were varied between 6 and 9. Figure 3 represents the results of simultaneous dye removal based on mean and $\mathrm{S} / \mathrm{N}$ versus $\mathrm{pH}$. As can be seen, optimum $\mathrm{pH}$ is 8.0 in level 3. For CR and $\mathrm{MG}$, the optimum $\mathrm{pH}$ is falling at basic pHs due to the formation of negative charges on the adsorbent surface; and at the same time, protonation of these two dyes [33]. For $\mathrm{RhB}$, the adsorption is high in acidic media and decreases with the increase in $\mathrm{pH}$ of the solution. It can be interpreted according to the $\mathrm{pK}_{\mathrm{a}}$ of $\mathrm{RhB}$ which is 3.7. Above this $\mathrm{pH}$, deprotonation of the carboxyl functional group occurs and therefore, an attraction between the carboxylate ion and the xanthene groups of the RhB results in the formation of dimers of the dye which results decreasing in adsorption, however this decrement is not very sharp in the $\mathrm{pH}$ interval we studied [34].

\section{Effect of adsorbent dosage}

What is illustrated in Fig. 4 is the effect of adsorbent dosage on percent of simultaneous removal of MG, RhB and CR dyes. As can be seen, due to the increment of the available sorption sites, percent of dye removing increases with increasing of adsorbent dosage. In order to study this effect by Taguchi method, experiments were designed with 4 levels of adsorbent in the range of $0.5-$ $2.5 \mathrm{~g}$. The optimum level for this factor is second level [23].

\section{Effect of ionic strength}

The salting-out effect is widely applied in traditional liquid-liquid extraction because it makes the solubility of organic targets in the aqueous phase decrease; thus, more analytes enter into extracting phase. In this study, the influence of salt on the adsorption process was studied at the presence of sodium chloride within the concentration range of 0.025 to $0.100 \mathrm{~g} \mathrm{~mL}^{-1}$. It was observed that changing the ionic strength has different effect on adsorption of different dyes (Additional file 1: Figure $\mathrm{S} 2$ ). By increasing the amount of $\mathrm{NaCl}$, the efficiency of removal of CR increased, while for the two other dyes, the efficiency was decreased. Due to the competition between cationic dyes (MG, $\mathrm{RhB}$ ) and $\mathrm{Na}^{+}$ions toward the available adsorption sites, by increasing the ionic strength, the activity of the dyes and the active sites of the sand decreases; hence, the amount of adsorption decreases [35]. On the other hand, for CR, any increase in the ionic strength of the solution leads to the repulsive electrostatic attraction, which leads to adsorption increase [36]. Optimum level for this factor was selected in level 3.

\section{Effect of contact time}

Removal of dyes by sand was carried out after 10, 20, 30 and $40 \mathrm{~min}$ of starting the adsorption process. Results are shown in Additional file 1: Figure S3. For RhB, when contact time increases, removal percent goes up and finally reaches to a constant level which deals with reaching equilibrium after $30 \mathrm{~min}$. However, for 

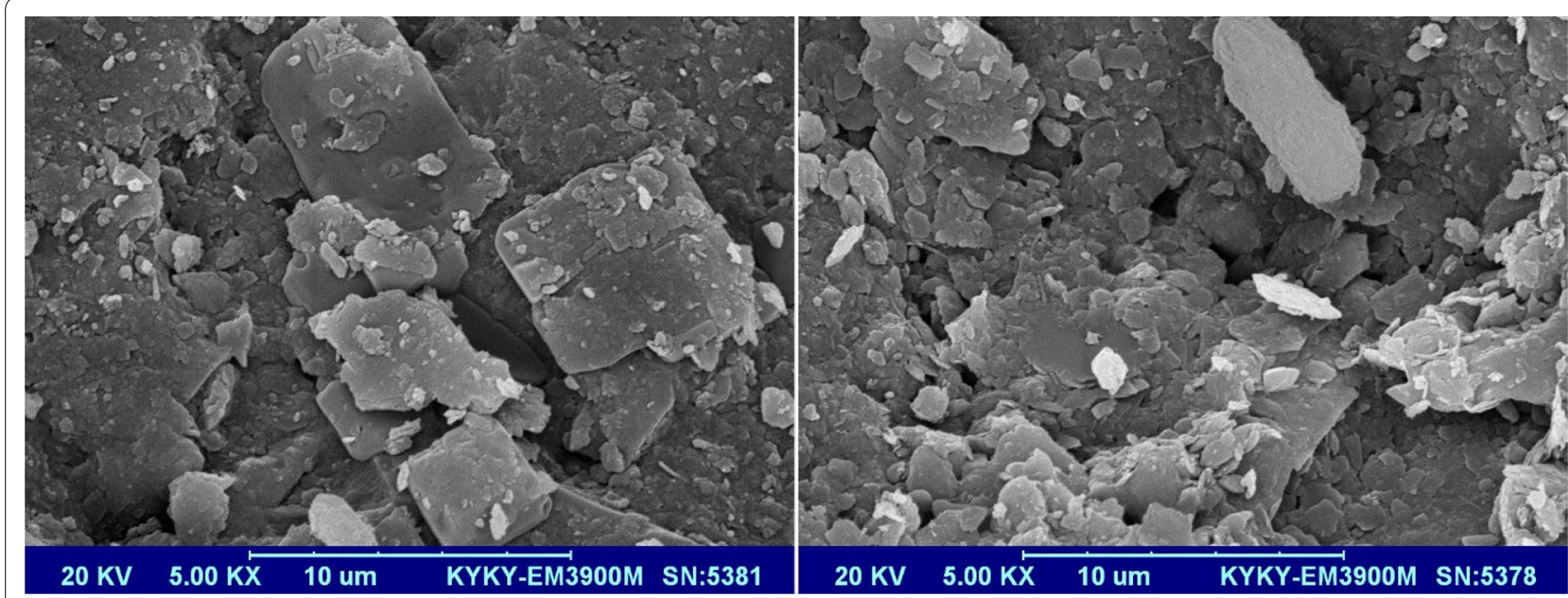

Fig. 2 SEM image of Sistan sand
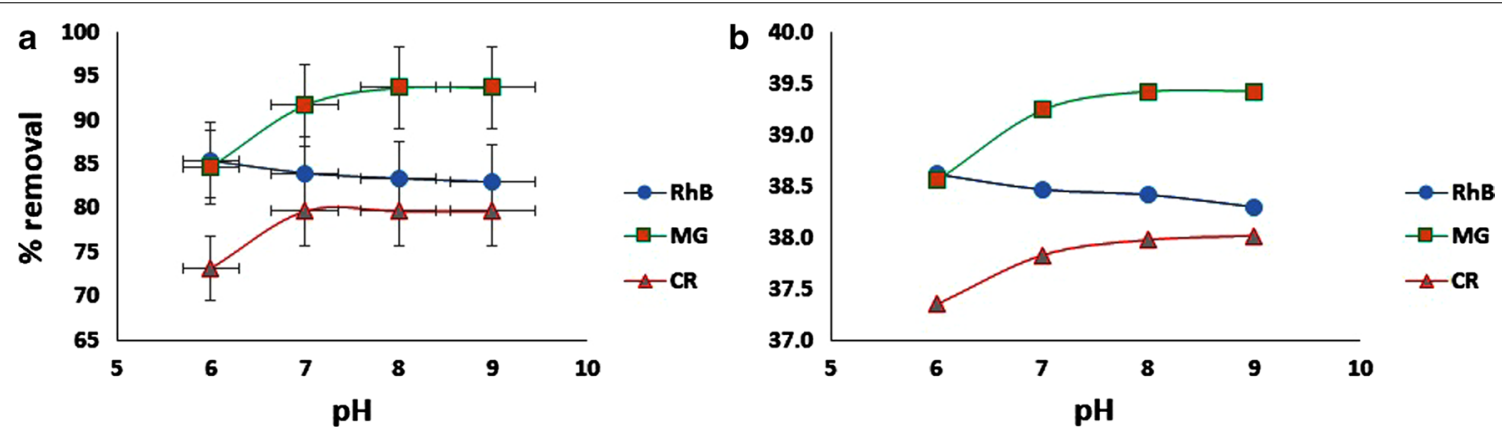

Fig. 3 Effect of $p H$ on removal of $M G, R h B$ and $C R$ based on Mean (a) and $S / N(\mathbf{b})$
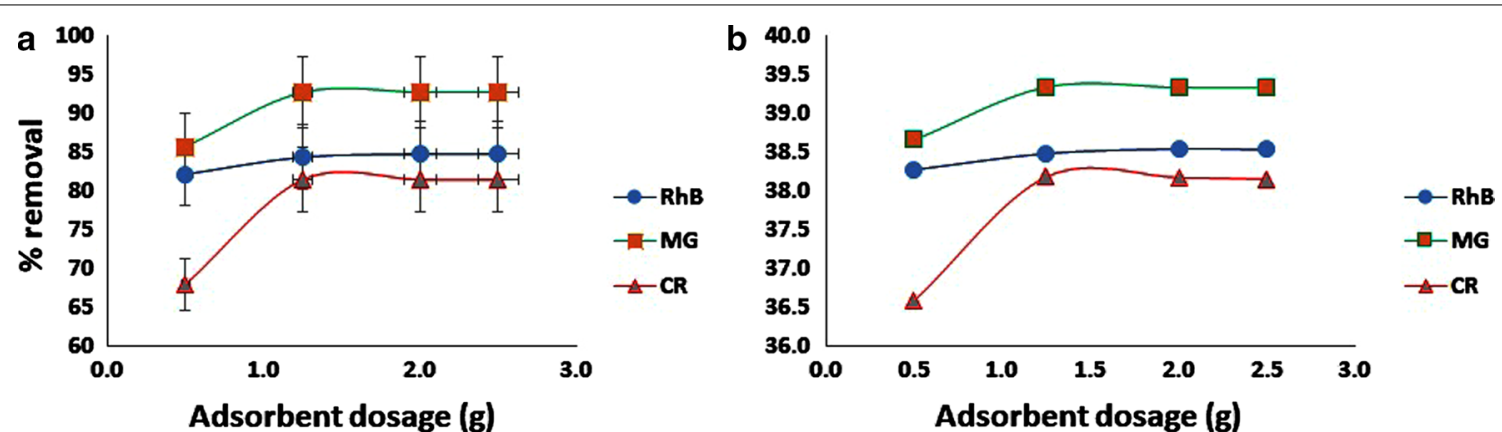

Fig. 4 Effect of adsorbent dosage on removal of MG, RhB and CR based on Mean (a) and S/N (b)

the two other dyes, after passing 20 min, the adsorption decreases. To have a balance for all dyes, the optimized contact time was selected at $20 \mathrm{~min}$ or second level. This phenomena occurs, probably due to the fact that while an equilibrium is attained, $\mathrm{RhB}$ can win the competition for available sites on the sand in long term.

\section{Effect of initial dye concentration}

Additional file 1: Figure S4, which is shown in supplementary data, shows the effect of initial dye concentration on simultaneous adsorption of the analytes on sand. To evaluate the effect of initial dye concentration solution were made which contain concentrations between 3 and $12 \mathrm{mg} \mathrm{L}^{-1}$ of each dye. It was found that by increasing the 
initial dye concentration, the efficiency reduces because of limited active site available on the sorbent [37]. The optimum conditions for this parameter selected $9 \mathrm{mg} \mathrm{L}^{-1}$ in level 3.

\section{Optimization process}

Participation and importance of each optimized factor was determined by ANOVA. In all factors, the optimal levels obtained through $\mathrm{S} / \mathrm{N}$ and the means are normally equal. An ideal result is one with the highest $\mathrm{S} / \mathrm{N}$ ratio [38]. Table 3 shows optimum levels for each factor. In order to verify that Taguchi has a perfect ability for response prediction., a comparison between predicted and practical results was performed. Results are mentioned in Table 4. In order to check the performance of prediction of Taguchi design method in this process, compliance percent is calculated according to equation (4):

$$
\text { Compliance percent }=\frac{\text { Practical result }}{\text { Predicted values }} \times 100
$$

Pure sum of square for a particular factor is calculated according to the following equation (5) [23]:

$$
\text { pure sum }=\text { sum of square }=V_{A} \times D O F
$$

where $V_{A}$ is the variance of $A$. ANOVA Analysis of variance was used to evaluate the orthogonal array of design results and is presented in Additional file 1: Table S2. The last column in the Table shows the contribution of each factor to the adsorption process.

\section{Plackett-Burman design}

In order to screen and find the best conditions for simultaneous removal of dyes, a Plackett-Burman design which is a multivariate strategy, was used. PBD is a two-level partial factorial design that can be used as an excellent screening tool to extract important information about the main factors affecting the system under study $[39,40]$. Here, it was used to identify the most effective parameters involved in the simultaneous adsorption of dyes. For this purpose, 5 factors were investigated in 2 levels. Additional file 1: Table S3 shows

Table 4 Practical and predicted values for dyes removal by using Taguchi method

\begin{tabular}{llll}
\hline Dyes & Predicted (\%) & Practical (\%) & $\begin{array}{l}\text { Compliance } \\
\text { percentage } \\
\text { (\%) }\end{array}$ \\
\hline MG & 93.98 & 96 & 97.89 \\
RhB & 78.25 & 82 & 95.43 \\
CR & 88.01 & 90 & 97.79 \\
\hline
\end{tabular}

the factors and levels at low $(-1)$ and high $(+1)$ levels of PBD. This method was designed by Minitab 16 software.

Results of experimental design for 12 experiments in 5 factors are plotted in Fig. 5, Additional file 1: Figures S5 and S6. Table 5 compares the priority of each of the factors studied in the PBD and Taguchi designs and reflects the conformance of the two methods.

\section{Kinetic study of adsorption}

In order to find the mechanism of adsorption of dyes on the sand, different kinetic models have been examined. The adsorption rate can be also predicted from kinetic parameters [41]. Eight experiments were carried out by OFAT method to study kinetic models. In this set of experiments, contact time was changed in the range of 1-30 min and other variables including $\mathrm{pH}$, adsorbent dosage, initial dye concentration and amount of $\mathrm{NaCl}$ were kept constant at their optimum level. Results of these experiments were investigated with the following pseudo first-order equation (6):

$$
\log \left(q_{e}-q_{t}\right)=\log q_{e}-\left(\frac{K_{1}}{2.303}\right) t
$$

where the amount of dye adsorbed at any time is shown as $\mathrm{q}_{\mathrm{t}}\left(\mathrm{mg} \mathrm{g}^{-1}\right), \mathrm{t}$ is contact time (min) and the pseudofirst order constant is $K_{1}\left(\mathrm{~min}^{-1}\right)$ [42]. By plotting the $\log \left(\mathrm{q}_{\mathrm{e}}-\mathrm{q}_{\mathrm{t}}\right)$ versus $\mathrm{t}, \mathrm{K}_{1}$ and $\mathrm{q}_{\mathrm{e}}$ were calculated from the slope and intercept of the plot, respectively. Pseudo second order was calculated by equation (7):

$$
\frac{t}{q_{t}}=\frac{1}{K_{2} q_{e}^{2}}+\frac{1}{q_{e}} t
$$

The adsorption rate constant of this model, $\mathrm{K}_{2}$ $\left(\mathrm{g} \mathrm{mg}^{-1} \mathrm{~min}^{-1}\right.$ ) is the pseudo-second order constant which was obtained from the intercept of the plot of $t / q_{t}$ against $t$. The slope of this plot shows $\mathrm{q}_{\mathrm{e}}$ [43]. Additional file 1: Table S4 presents the kinetic parameters for simultaneous adsorption of MG, RhB and CR on Sistan sand, and reveals that pseudo second order is the best fitted model for kinetic of removal of them. A similar observation is reported in adsorption of reactive orange 16 [44].

\section{Thermodynamics studies}

The thermodynamic parameters such as changing the enthalpy $\left(\Delta \mathrm{H}^{\circ}\right)$, entropy change $\left(\Delta \mathrm{S}^{\circ}\right)$ and Gibbs free energy $\left(\Delta G^{\circ}\right)$ represent some information which confirms adsorption nature and are useful to evaluate the feasibility and the spontaneous nature of adsorption. Van't Hoff plot (Eq. 8) was used to calculate $\Delta \mathrm{H}^{\circ}$ and $\Delta \mathrm{S}^{\circ}$ of each dye adsorbed on the sand from the slope and intercept of this plot, respectively. 


\section{Main Effects Plot for Malachite Green removing \\ Data Means}

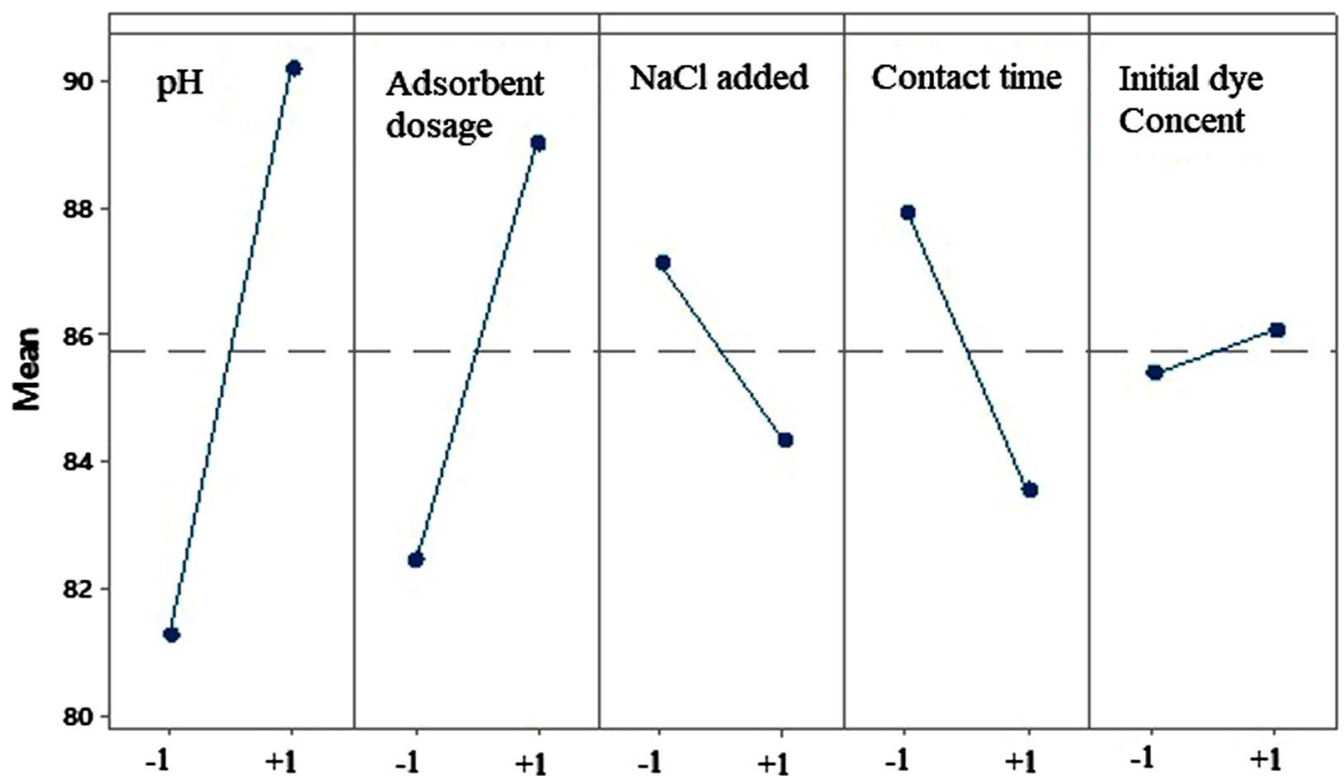

Fig. 5 Main effects plot for MG removal by PBD

Table 5 The effectiveness of factors in PBD and Taguchi design

\begin{tabular}{|c|c|c|c|c|c|c|}
\hline \multirow[t]{2}{*}{ Effectiveness } & \multicolumn{3}{|c|}{ Plackett-Burman design } & \multicolumn{3}{|l|}{ Taguchi design } \\
\hline & MG & RhB & CR & MG & RhB & $\mathrm{CR}$ \\
\hline 1 & $\mathrm{pH}$ & $\begin{array}{l}\text { Initial dye concen- } \\
\text { tration }\end{array}$ & $\begin{array}{l}\text { Initial dye concen- } \\
\text { tration }\end{array}$ & Adsorbent dosage & $\begin{array}{l}\text { Initial dye concen- } \\
\text { tration }\end{array}$ & Adsorbent dosage \\
\hline 2 & Adsorbent dosage & lonic strength & Adsorbent dosage & $\mathrm{pH}$ & Contact time & $\begin{array}{l}\text { Initial dye concen- } \\
\text { tration }\end{array}$ \\
\hline 3 & Contact time & Contact time & lonic strength & Ionic strength & lonic strength & Ionic strength \\
\hline 4 & lonic strength & Adsorbent dosage & Contact time & $\begin{array}{l}\text { Initial dye concen- } \\
\text { tration }\end{array}$ & Adsorbent dosage & Contact time \\
\hline 5 & $\begin{array}{l}\text { Initial dye concen- } \\
\text { tration }\end{array}$ & $\mathrm{pH}$ & $\mathrm{pH}$ & Contact time & $\mathrm{pH}$ & $\mathrm{pH}$ \\
\hline
\end{tabular}

$$
\log \left(\frac{q_{e}}{C_{e}}\right)=\frac{\Delta \mathrm{S}^{\circ}}{2.303 R}-\frac{\Delta \mathrm{H}^{\circ}}{2.303 R T}
$$

where $\mathrm{R}\left(8.304 \mathrm{~J} \mathrm{~mol}^{-1} \mathrm{~K}^{-1}\right)$ is the universal gas constant and $\mathrm{T}$ is the absolute temperature of the solution (K). $\Delta \mathrm{G}^{\circ}$ was calculated from equation (9) [45]:

$$
\Delta \mathrm{G}^{\circ}=\Delta \mathrm{H}^{\circ}-\mathrm{T} \Delta \mathrm{S}^{\circ}
$$

In order to determine the thermodynamic parameters of simultaneous removal of MG, RhB and CR, 4 experiments were carried out by OFAT method. All experimental conditions were kept constant and temperature was varied. What are tabulated in Additional file 1:
Table S5 are the values of the above parameters. It is clear that positive $\Delta \mathrm{H}^{\circ}$ represents that the adsorption process is endothermic. Positive $\Delta S^{\circ}$ reveals that there is an increase in randomness between the 2 phases (solid/liquid) in solution. According to the values obtained for $\Delta \mathrm{G}^{\circ}$, the spontaneous of the simultaneous adsorption of three dyes by Sistan sand is confirmed. Total values of the thermodynamic parameters reveal that this process take place through electrostatic interactions [46].

\section{Real sample analysis}

In order to study the efficiency of the method for simultaneous removal of $\mathrm{MG}, \mathrm{RhB}$, and $\mathrm{CR}$ from water samples, 
Table 6 A comparison on removal of MG, RhB and CR by different adsorbents

\begin{tabular}{|c|c|c|c|c|}
\hline No & Adsorbent & Adsorbate & qe $\left(\mathrm{mg} \mathrm{g}^{-1}\right)$ & References \\
\hline 1 & Sahara desert sand & Methylene Blue & 11.98 & [47] \\
\hline 2 & Feldspar & Methylene Blue & 0.66 & [48] \\
\hline 3 & Bentonite & MG & 7.72 & [49] \\
\hline 4 & 3A zeolite & $\operatorname{RhB}$ & 0.74 & [23] \\
\hline 5 & Zeolite MCM-22 & $\operatorname{RhB}$ & 1.11 & {$[50]$} \\
\hline 6 & Beach sand coated with polyaniline & Methylene Blue & 9.10 & {$[51]$} \\
\hline 7 & Gypsum & Methylene Blue & 36.00 & {$[52]$} \\
\hline 8 & functionalized multi walled carbon nanotubes & MG & 114.11 & {$[53]$} \\
\hline 9 & Albizzia lebbeck seed activated carbon & $C R$ & 5.154 & {$[54]$} \\
\hline 10 & magnetic $\mathrm{Fe}_{3} \mathrm{O}_{4} / \mathrm{C}$ core-shell nanoparticles & $C R$ & 11.22 & {$[55]$} \\
\hline 11 & Sistan sand & $\begin{array}{l}\text { Simultaneous removal of } M G \text {, } \\
\text { RhB and CR }\end{array}$ & 0.36 & This study \\
\hline
\end{tabular}

a $20 \mathrm{~mL}$ aliquot of tap water was spiked with $9 \mathrm{mg} \mathrm{L}^{-1}$ of each dye. Sistan sand was applied as adsorbent under optimal conditions. Spectrophotometry showed that the percentage removal of dyes for MG, RhB, and CR obtained were $92 \%, 76 \%$ and $83 \%$, respectively. Also, using equation [2], $\mathrm{q}_{\mathrm{e}}$ for MG, RhB, and CR was calculated to be $0.133,0.109$, and $0.120 \mathrm{mg}$ of dye per $\mathrm{g}$ of the sand, respectively. In Table 6, some other sorbents reported in the literature were compared with the Sistan sand for the adsorption of the same organic dyes. While the most of the other sorbents need pretreatments or modifications, Sistan sand which is costless and is plenty available, still has good performance for simultaneous removal of dyes.

\section{Conclusion}

In this study, Sistan sand as a costless and accessible sorbent was used for simultaneous removal of three dyes Malachite green, Rhodamine B and Cresol red from water sample. Optimum conditions for adsorption was designed and predicted by Taguchi method and was determined experimentally. Plackett-Burman design was used to confirm the Taguchi design and as a screening method to identify the significance of each factor influencing this process. In almost all cases, a good agreement between these Taguchi and PBD was observed. Kinetic studies showed that pseudo second order is the best fitted model for all three analytes. This process is endothermic, as thermodynamic studies showed. We also demonstrated that simultaneous adsorption of environmental pollutants, especially dyes, are plainly achievable, even when the nature of target compounds are different.

\section{Additional file}

Additional file 1: Table S1. Factors and levels in Taguchi design to remove $M G$, RhB and CR. Figure S1. FT-IR of Sistan sand. Figure S2. Effect of ionic strength on removal of $M G, R h B$ and $C R$ based on Mean (A) and

$\mathrm{S} / \mathrm{N}$ (B). Figure S3. Effect of contact time on concurrent adsorption based on Mean (A) and S/N ratio (B). Figure S4. Effect of initial dye concentration on simultaneous adsorption based on Mean (A) and $\mathrm{S} / \mathrm{N}$ ratio (B). Table S2. ANOVA results for simultaneous removal of $M G, R h B$ and $C R$. Table S3. Factors and levels were used for concurrent adsorption of MG, $\mathrm{RhB}$ and CR in PBD. Figure S5. Main effects plot for RhB removal by PBD. Figure S6. Main effects plot for CR removal by PBD. Table S4. Kinetic parameters of simultaneous removal of MG, RhB and CR by Sistan sand. Table S5. Thermodynamic parameters on simultaneous removal of MG, $\mathrm{RhB}$ and $\mathrm{CR}$.

\section{Abbreviations}

MG: Malachite Green; RhB: Rhodamine B; CR: Cresol Re; OFAT: one-factor-ata-time; DOE: design of experiment; FT-IR: Fourier transform; SEM: scanning electron microscope; ANOVA: analysis of variance; $\mathrm{S} / \mathrm{N}$ : signal to noise; SNR: signal to noise ratio; PBD: Plackett-Burman design.

\section{Authors' contributions}

SM, MS and MS did the practical work. Both MK and Moj S co-wrote the manuscript and MK planned the study. MH gave his laboratory and instruments for doing experiments. All authors read and approved the final manuscript.

\section{Author details}

${ }^{1}$ Department of Chemistry, Faculty of Sciences, University of Sistan and Baluchestan, Zahedan 98155-674, Iran. ${ }^{2}$ Young Researchers and Elite Club, Zahedan Branch, Islamic Azad University, Zahedan, Iran. ${ }^{3}$ Smartphone Analytical Sensors Research Centre, University of Sistan and Baluchestan, Zahedan, Iran. ${ }^{4}$ Department of Clinical Biochemistry, School of Medicine, Zahedan University of Medical Science, Zahedan, Iran.

\section{Acknowledgements}

This research was supported by The University of Sistan and Baluchestan and Zahedan University of Medical Sciences.

\section{Competing interests}

The authors declare that they have no competing interests.

\section{Availability of data and materials}

All data generated or analyzed during this study are included in this published article and its supplementary information files. 


\section{Funding}

This work is not funded.

\section{Publisher's Note}

Springer Nature remains neutral with regard to jurisdictional claims in published maps and institutional affiliations.

Received: 28 July 2018 Accepted: 8 November 2018 Published online: 16 November 2018

\section{References}

1. Jafari S, Zhao F, Zhao D, Lahtinen M, Bhatnagar A, Sillanpää M (2015) A comparative study for the removal of methylene blue dye by $\mathrm{N}$ and $\mathrm{S}$ modified $\mathrm{TiO}_{2}$ adsorbents. J Mol Liq 207(90):8

2. Shojaei S, Khammarnia S, Shojaei S, Sasani M (2017) Removal of reactive red 198 by nanoparticle zero valent iron in the presence of hydrogen peroxide. J Water Environ Nanotechnol 2(2):129-135

3. Yagub MT, Sen TK, Afroze S, Ang HM (2014) Dye and its removal from aqueous solution by adsorption: a review. Adv Colloid Interface Sci 209:172-184

4. Wang S, Boyjoo Y, Choueib A, Zhu Z (2005) Removal of dyes from aqueous solution using fly ash and red mud. Water Res 39(1):129-138

5. Jorfi S, Barzegar G, Ahmadi M, Soltani RDC, Takdastan A, Saeedi R, Abtahi M (2016) Enhanced coagulation-photocatalytic treatment of acid red 73 dye and real textile wastewater using UVA/synthesized MgO nanoparticles. J Environ Manage 177:111-118

6. Holkar CR, Jadhav AJ, Pinjari DV, Mahamuni NM, Pandit AB (2016) A critical review on textile wastewater treatments: possible approaches. J Environ Manage 182:351-366

7. Shojaei S, Shojaei S, Sasani M (2017) The efficiency of eliminating direct red 81 by zero-valent iron nanoparticles from aqueous solutions using response surface Model (RSM). Model Earth Syst Environ 3(1):27

8. Banerjee S, Chattopadhyaya M (2017) Adsorption characteristics for the removal of a toxic dye, tartrazine from aqueous solutions by a low cost agricultural by-product. Arabian J Chem 10:S1629-S1638

9. Mani S, Bharagava RN (2016) Exposure to crystal violet, its toxic, genotoxic and carcinogenic effects on environment and its degradation and detoxification for environmental safety. Rev Environ Contam Toxicol 237:71-104

10. Seow TW, Lim CK (2016) Removal of dye by adsorption: a review. Int J Appl Eng Res 11(4):2675-2679

11. Rahmani M, Sasani M (2016) Evaluation of 3 A zeolite as an adsorbent for the decolorization of rhodamine B dye in contaminated waters. J Appl Chem (Semnan) 11(41):83-90

12. Zolgharnein J, Rastgordani M (2018) Optimization of simultaneous removal of binary mixture of indigo carmine and methyl orange dyes by cobalt hydroxide nano-particles through Taguchi method. J Mol Liq 262:405-414

13. Dashamiri S, Ghaedi M, Dashtian K, Rahimi MR, Goudarzi A, Jannesar $R$ (2016) Ultrasonic enhancement of the simultaneous removal of quaternary toxic organic dyes by CuO nanoparticles loaded on activated carbon: central composite design, kinetic and isotherm study. Ultrason Sonochem 31:546-557

14. Kaykhaii M, Sasani M, Marghzari S (2018) Removal of dyes from the environment by adsorption process. Chem Mater Eng 6(2):31-35

15. Nooraee-Nia N, Rahmani M, Kaykhaii M, Sasani M (2017) Evaluation of eucalyptus leaves as an adsorbent for decolorization of methyl violet (2B) dye in contaminated waters: thermodynamic and kinetics model. Model Earth Syst Environ 3(2):825-829

16. Bukallah SB, Rauf MA, AIAli SS (2007) Removal of methylene blue from aqueous solution by adsorption on sand. Dyes Pigm 74(1):85-87

17. Halim AA, Han KK, Hanafiah MM (2015) Removal of methylene blue from dye wastewater using river sand by adsorption. Nat Environ Pollut Technol 14(1):89

18. Simonovic K, Kalin M (2016) Methodology of a statistical and DOE approach to the prediction of performance in tribology - a DLC boundary-lubrication case study. Tribol Int 101:10-24
19. Niedz RP, Evens TJ (2016) Design of experiments (DOE)—history, concepts, and relevance to in vitro culture. Vitro Cell Dev Biol Plant 52(6):547-562

20. Pundir R, Chary GHVC, Dastidar MG (2016) Application of Taguchi method for optimizing the process parameters for the removal of copper and nickel by growing Aspergillus sp. Water Resour Ind. https://doi. org/10.1016/j.wri.2016.05.001

21. Durakovic B (2017) Design of experiments application, concepts, examples: state of the art. Per Eng Nat Sci 5(3):421-439

22. Ekpenyong MG, Antai SP, Asitok AD, Ekpo BO (2017) Plackett-Burman design and response surface optimization of medium trace nutrients for Glycolipopeptide biosurfactant production. Iran Biomed J 21 (4):249

23. Rahmani M, Kaykhaii M, Sasani M (2015) Application of Taguchi L16 design method for comparative study of ability of $3 \mathrm{~A}$ zeolite in removal of rhodamine $B$ and malachite green from environmental water samples. Spectrochim Acta Part A 188:164-169

24. Sohrabi MR, Khavaran A, Shariati S, Shariati S (2017) Removal of carmoisine edible dye by fenton and photo fenton processes using Taguchi orthogonal array design. Arabian J Chem 10:\$3523-S3531

25. Edrissi M, Samadanian-Isfahani S, Soleymani M (2017) Preparation of cobalt molybdate nanoparticles; Taguchi optimization and photocatalytic oxidation of reactive black 8 dye. Powder Technol 249:378-385

26. Han R, Zou W, Zhang Z, Shi J, Yang J (2006) Removal of copper(II) and lead(II) from aqueous solution by manganese oxide coated sand: I. Characterization and kinetic study. J Hazard Mater 137(1):384-395

27. Zhang JZ, Chen JC, Kirby ED (2007) Surface roughness optimization in an end-milling operation using the Taguchi design method. J Mater Process Technol 184(1-3):233-239

28. Wp Yang, Tarng Y (1998) Design optimization of cutting parameters for turning operations based on the Taguchi method. J Mater Process Technol 84(1-3):122-129

29. Gopalsamy BM, Mondal B, Ghosh S (2009) Taguchi method and ANOVA: an approach for process parameters optimization ofhard machining while machining hardened steel. J Sci Ind Res 68:686-695

30. He Z, Zhou J (2008) Empirical evaluation of a new method for calculating signal-to-noise ratio for microarray data analysis. Appl Environ Microbiol 74(10):2957-2966

31. Daneshvar N, Khataee AR, Rasoulifard MH, Pourhassan M (2007) Biodegradation of dye solution containing malachite green: optimization of effective parameters using Taguchi method. J Hazard Mater 143(1):214-219

32. Paluszkiewicz C, Holtzer M, Bobrowski A (2008) FTIR analysis of bentonite in moulding sands. J Mol Struct 880(1):109-114

33. Kausar A, lqbal M, Javed A, Aftab K, Z-i-H Nazli, Bhatti HN, Nouren S (2018) Dyes adsorption using clay and modified clay: a review. J Mol Liq 256:395-407

34. Gupta V, Suhas Ali I, Saini V (2004) Removal of rhodamine B, fast green, and methylene blue from wastewater using red mud, an aluminum industry waste. Ind Eng Chem Res 43(7):1740-1747

35. Kushwaha AK, Gupta N, Chattopadhyaya MC (2014) Removal of cationic methylene blue and malachite green dyes from aqueous solution by waste materials of Daucus carota. J Saudi Chem Soc 18(3):200-207

36. Al-Degs YS, El-Barghouthi MI, El-Sheikh AH, Walker GM (2008) Effect of solution $\mathrm{pH}$, ionic strength, and temperature on adsorption behavior of reactive dyes on activated carbon. Dyes Pigm 77(1):16-23

37. De Gisi S, Lofrano G, Grassi M, Notarnicola M (2016) Characteristics and adsorption capacities of low-cost sorbents for wastewater treatment: a review. Sustain Mater Technol 9:10-40

38. De-chun G, Gang H, Xiao-Dong W, Chun-Yan Y, Guang-Rong Q, Rong L, Da-fu D (1992) Experimental study of the signal-to-noise ratio of stochastic resonance systems. Phys Rev A 46(6):3243

39. Bahloul L, Ismail F, Samar ME-H (2014) Meradi H. Removal of AY99 from an aqueous solution using an emulsified liquid membrane. Application of Plackett-Burman design. Energy Procedia 50:1008-1016

40. Phung Y-P, Ong S-T, Keng P-S (2013) Determination of important parameters in affecting the uptake of reactive black 5 by chitosan beads through statistical approach. J Chem. https://doi.org/10.1155/2013/387865

41. Mahmoodi NM, Maghsoodi A (2015) Kinetics and isotherm of cationic dye removal from multicomponent system using the synthesized silica nanoparticle. Desalin Water Treat 54(2):562-571

42. Dahri MK, Kooh MRR, Lim LB (2014) Water remediation using low cost adsorbent walnut shell for removal of malachite green: equilibrium, 
kinetics, thermodynamic and regeneration studies. J Environ Chem Eng 2(3):1434-1444

43. Sartape AS, Mandhare AM, Jadhav VV, Raut PD, Anuse MA, Kolekar SS (2017) Removal of malachite green dye from aqueous solution with adsorption technique using Limonia acidissima (wood apple) shell as low cost adsorbent. Arabian J Chem 10:S3229-S3238

44. Oyelude EO, Awudza JAM, Twumasi SK (2017) Equilibrium, kinetic and thermodynamic study of removal of eosin yellow from aqueous solution using Teak Leaf Litter powder. Sci Rep 7(1):12198

45. De Castro MLFA, Abad MLB, Sumalinog DAG, Abarca RRM, Paoprasert P, de Luna MDG (2018) Adsorption of methylene blue dye and $\mathrm{Cu}(I)$ ions on EDTA-modified bentonite: isotherm, kinetic and thermodynamic studies. Sustain Environ Res 28(5):197-205

46. Mahmoodi NM, Sadeghi U, Maleki A, Hayati B, Najafi F (2014) Synthesis of cationic polymeric adsorbent and dye removal isotherm, kinetic and thermodynamic. J Ind Eng Chem 20(5):2745-2753

47. Varlikli C, Bekiari V, Kus M, Boduroglu N, Oner I, Lianos P, Lyberats G, Icli S (2009) Adsorption of dyes on sahara desert sand. J Hazard Mater 170(1):27-34

48. Awala H, El Jamal M (2011) Equilibrium and kinetics study of adsorption of some dyes onto feldspar. J Univ Chem Technol Metall 46(1):221-228
49. Tahir S, Rauf N (2006) Removal of a cationic dye from aqueous solutions by adsorption onto bentonite clay. Chemosphere 63(11):842-848

50. Wang S, Li H, Xu L (2006) Application of zeolite MCM-22 for basic dye removal from wastewater. J Colloid Interface Sci 295(1):71-78

51. Ansari R, Mohammad-khah A, Nazmi M (2013) Application of chemically modified beach sand as low cost efficient adsorbent for dye removal. Curr Chem Lett 2(4):215-223

52. Rauf MA, Shehadeh I, Ahmed A, Al-Zamly A (2009) Removal of methylene blue from aqueous solution by using gypsum as a low cost adsorbent. Int J Chem Biol Eng 55:608-613

53. Shirmardi M, Mahvi AH, Hashemzadeh B, Naeimabadi A, Hassani G, Niri MV (2013) The adsorption of malachite green (MG) as a cationic dye onto functionalized multi walled carbon nanotubes. Korean J Chem Eng 30(8):1603-1608

54. Bhuvaneswari R, Arivalagan K, Tamilarasan R (2017) Isotherms, kinetics and thermodynamics of adsorption study in dye removal of Albizzia Lebbeck seed activated carbon. Int J Innov Res Adv Stud 4(11):108-113

55. Zhang Z, Kong J (2011) Novel magnetic Fe3O4@C nanoparticles as adsorbents for removal of organic dyes from aqueous solution. J Hazard Mater 193:325-329
Ready to submit your research? Choose BMC and benefit from:

- fast, convenient online submission

- thorough peer review by experienced researchers in your field

- rapid publication on acceptance

- support for research data, including large and complex data types

- gold Open Access which fosters wider collaboration and increased citations

- maximum visibility for your research: over 100M website views per year

At BMC, research is always in progress.

Learn more biomedcentral.com/submissions 